\title{
Kreft og dødelighet blant norske feiere: Vurdering av datakvalitet
}

\author{
Bjørn Møller og Aage Andersen \\ Kreftregisteret, Institute of population-based cancer research, 0310 Oslo \\ Korrespondanse: Bjørn Møller, telefon: 23333913 e-post: bjorn.moller@kreftregisteret.no
}

\section{ENGLISH SUMMARY}

Møller B, Andersen Aa. Cancer and mortality among Norwegian chimney sweeps. Nor J Epidemiol 2001; 11 (2): 193-196.

\begin{abstract}
The aim of the study was to investigate cancer incidence and mortality among Norwegian chimney sweeps. A cohort of 1483 persons was established by collecting information about current and former chimney sweeps from all the local authorities. Information from housing censuses (HS) in 1960, 1970 and 1980 were used to study the quality of the data. This revealed that the mortality among those chimney sweeps in HS that are included in our cohort is lower than the mortality among those not reported to us from the local authorities. Because of this, only a sub-cohort of 287 chimney sweeps from the largest cities were considered reliable. The uncertainty concerning risks for the different cancer sites in this group is large, since calculations are based on very few cases. The standardized incidence rate (SIR) for total cancer is 1.3 (95\% CI: $1.0-1.8)$, and the standardized mortality rate (SMR) for all deaths is 1.2 (95\% CI: $1.0-1.4)$. We also analyzed the 1292 persons who stated chimney sweep as occupation in the housing censuses in 1960, 1970 or 1980. SIR and SMR analyses in this group show no increased risk for any specific cancer sites, nor for any cause specific death.
\end{abstract}

\section{INNLEDNING}

Feiere er i sitt arbeidsmiljø særlig utsatt for sot og asbest. Sot er definert som biprodukt av ufullstendig forbrenning av karbon-inneholdende materiale. Sot kan også inneholde ulike kreftfremkallende stoffer som arsen, kadmium, krom, nikkel og ikke minst tjærestoffer (1). En kohort-studie av 5542 svenske feiere (2) viser en overhyppighet av kreft, og en høyere dødelighet enn normalbefolkningen.

En kartlegging av kreftforekomst og dødelighet for en yrkesgruppe baserer seg på at en kan etablere en valid kohort. I Norge finnes det ikke samlede historiske registre over personer som er eller har vært feiere, til tross for at de fleste feierne i Norge har vært medlemmer av et fagforbund. Feierne er hovedsakelig ansatt av kommunene, så den eneste muligheten for å etablere en kohort er å innhente informasjon om feiere direkte fra den enkelte kommune. Denne retrospektive måten å samle inn data på kan potensielt føre til skjevheter på grunn av over- eller underrapportering av blant annet døde personer.

I Bergen ble kommunal feiing lovbestemt i 1707 (3). Etter dette har feiertjenesten gradvis blitt innført $i$ resten av landets kommuner. Først i 1970 ble alle kommuner lovpålagt å ha et feiervesen. Det er hensiktsmessig å skille ut storbyene Oslo, Bergen, Trondheim og Stavanger. Disse har hatt kommunalt feier- vesen siden før 1920 (3) og har levert komplette lister over nåværende og tidligere feiere. Når det gjelder resten av kommunene, er rapporteringen delvis basert på arkivbaserte lister, delvis på informasjon fra enkeltpersoner. Formålet med denne studien å presentere tall for kreftforekomst og dødelighet for norske feiere. Preliminære resultater tyder på inkomplette data, derfor er informasjon fra Folke og Boligtellingene benyttet for å evaluere seleksjonsproblemet.

\section{MATERIALE OG METODE}

Alle 444 kommuner (pr 1998) i Norge ble tilskrevet og bedt om å sende inn informasjon om personer som er eller tidligere har vært ansatt som feier. Lister med fødselsdato og dato for start og slutt som feier ble returnert fra 269 av kommunene. Disse kommunene representerer $80,4 \%$ av den norske befolkning. Til sammen kom det inn informasjon om 1605 personer.

Kreftregisteret har registrert kreftforekomst i befolkningen siden 1953, etter kodesystemet ICD-7. Statistisk sentralbyrå registrerer dødsårsaker, og data er tilgjengelige i ICD-9 koder for perioden 1951-1996. Alle innbyggere i Norge har, siden 1964, et unikt personnummer. Kreftforekomst og dødsårsak kobles ved personnummer for personer som har dette, og ved kombinasjonen navn og fødselsdato for personer som ikke har personnummer. 
Kreftforekomst er tilgjengelig for perioden 19531998, 10 personer som startet å arbeide som feier etter 1998 er ekskludert. Femtisyv personer kunne ikke kobles, enten fordi vi hadde feil informasjon om navn eller fødselsdag, eller fordi de døde før 1953. Til slutt ble 55 personer ekskludert fordi det ikke forelå informasjon om start som feier. Dette gav en kohort på 1483 personer til å følge opp med hensyn på kreftforekomst. En subkohort av feiere i storbyer, definert ved Oslo, Bergen, Trondheim og Stavanger, utgjør 287 feiere. Oppfølging med hensyn på dødsårsak skjer i perioden 1951-1996, hvilket gir en kohort på 1406 personer. Av disse er 286 fra storbyene.

Folke og Boligtellingen (FoB) 1960, 1970 og 1980 inneholder informasjon om hvem som er feiere det respektive året. Ved å koble en yrkeskohort mot FoB kan man indirekte kvantifisere størrelsen på en seleksjonsbias, hvilket er gjort ved å sammenlikne dødeligheten blant de feierne i FoB som er med i vår kohort med de feierne i FoB som ikke har kommet med i vår kohort.

Informasjon om yrke fra FoB 1960, 1970 og 1980 foreligger $\mathrm{i}$ en anonymisert fil ved Kreftregisteret. Filen inneholder blant annet informasjon om yrke og næring, fødselsmåned, fødselsår og bostedskommune for 1292 feiere. Filen inneholder også informasjon om kreftforekomst, dato for kreft og dato for død ut 1993, samt dødsårsak ut 1991. Feierne fra FoB blir fulgt opp fra første gang de ble registrert i FoB, dvs fra 1960, 1970 eller 1980.

Filen fra FoB er koblet til feier-kohorten ved å bruke fødselsmåned, fødselsår, yrke og bostedskommune. Figur 1 viser at totalt 947 personer har oppgitt feier som yrke enten i 1960, 1970 eller 1980, med bostedskommune blant de 269 kommunene som har rapportert feiere til vår kohort. Ved å koble på bodstedskommune, vil feiere som bor i en kommune, men som arbeider som feier i en annen kommune, havne i gruppen som (tilsynelatende) ikke er inkludert $i$ kohorten.

Standardisert mortalitetsrate (SMR) er beregnet som forholdet mellom observert antall døde i kohorten og forventet antall døde basert på alder, periode og kjønns-spesifikke rater i populasjonen. Standardisert insidensrate (SIR) for kreftforekomst er beregnet på tilsvarende måte. Konfidensintervall $(95 \%)$ er beregnet, basert på antagelse om Poissonfordeling av antall tilfeller. Test for likhet mellom to SMR er basert på at to Poissonfordelte variable, gitt summen av de to, er binomisk fordelt (4). Analysene er utført ved hjelp av programpakken EPICURE (5).

\section{RESULTATER}

Tabell 1 viser at de 389 feierne i FoB som vi ikke har fătt informasjon fra, har en signifikant høyere dødelighet $(\mathrm{SMR}=1,22)$ enn de 390 feierne i FoB som er rapportert til kohorten $(\mathrm{SMR}=0,65)$. Dette kan bety at for de mindre kommunene, har døde feiere en lavere sannsynlighet for å komme med i kohorten enn feiere som fortsatt er i live. Det samme bildet tegner seg for kreftformer med høy dødelighet, mens seleksjonsproblemet ikke kan vises for kreftformer med relativt sett lavere dødelighet. På grunn av denne mulige underrapporteringen av døde mennesker, er det kun resultater fra subkohorten av feiere i storbyene som ansees som pålitelige, og resultater fra hele kohorten er derfor ekskludert fra analysen. Blant de 134 storbyfeierne fra FoB som er kommet med i kohorten, er $\operatorname{SMR}=1,23$, mens den er 1,04 for de 34 som ikke er inkludert i kohorten (p-verdi for differanse: 0,75 ). Kriteriene for å bli karakterisert som ikke i kohorten, er at kombinasjonen av fødselsmåned, fødselsår og bostedskommune for en feier i FoB ikke finnes i vår innsamlede kohort. Ved å koble på bostedskommune, vil feiere som bor i en kommune, men som arbeider som feier $i$ en annen kommune derfor havne i gruppen som (tilsynelatende) ikke er inkludert i kohorten. Hvis man kobler kun på yrke, fødselsmåned og fødselsår (og ikke kommune), vil kun 6 av de 34 storby-feierne (9\%) fortsatt bli markert som "ikke i kohorten". Tilsvarende tall for de mindre kommunene er 123 av 389 (32\%).

Figur 1. Fordeling av de feierne fra FoB som har bostedskommune blant de kommunene som har rapportert feiere til vår utgangs-kohort, etter storbystatus og tilhørighet.

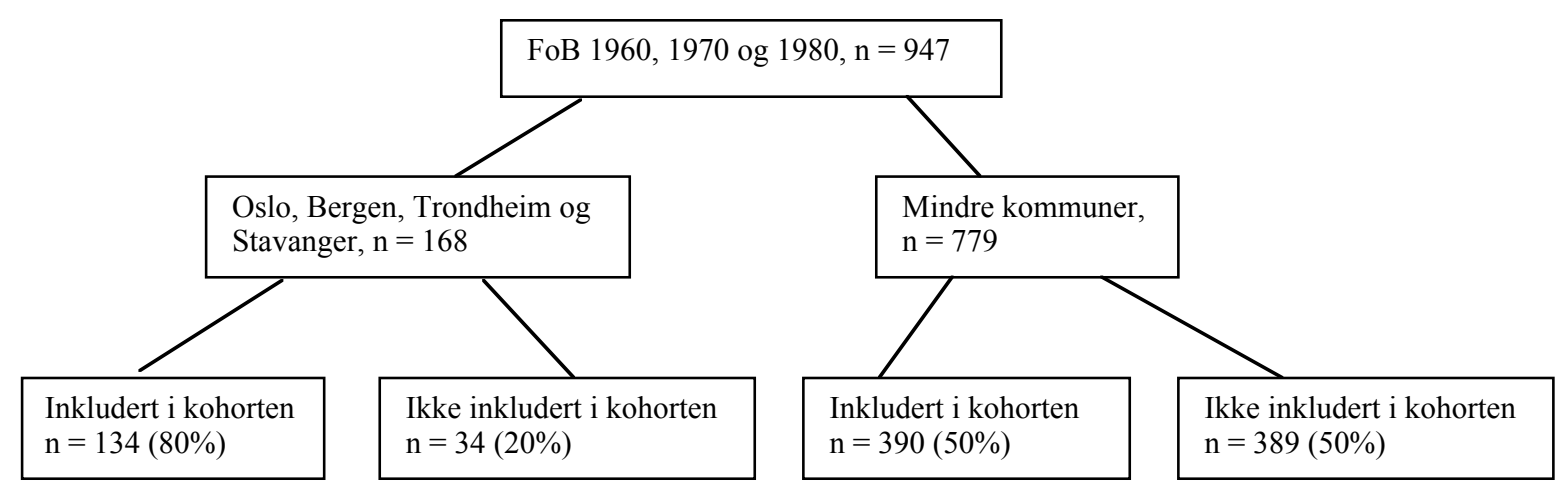


Tabell 1. SIR og SMR for 779 feiere fra folke og boligtellingen i 1960, 1970 eller 1980, storbyene og kommuner som ikke har rapportert til vår kohort er ekskludert.

\begin{tabular}{lcccc}
\hline & $\begin{array}{c}\text { Observert } \\
\text { antall }\end{array}$ & $\begin{array}{c}\text { SIR/ } \\
\text { SMR }^{\mathfrak{}}\end{array}$ & $\begin{array}{c}95 \% \text { konfidens- } \\
\text { intervall }\end{array}$ & $\begin{array}{c}\text { P-verdi }^{\ell} \text { for } \\
\text { differanse }\end{array}$ \\
\hline Kreftformer med lav overlevelse & & & & 0,11 \\
$\quad$ Inkludert i kohorten $(\mathrm{n}=390)$ & 12 & 0,78 & $(0,4-1,4)$ & \\
$\quad$ Ikke inkludert i kohorten $(\mathrm{n}=389)$ & 29 & 1,42 & $(1,0-2,0)$ & \\
Kreftformer med høy overlevelse & & & & 0,54 \\
$\quad$ Inkludert i kohorten $(\mathrm{n}=390)$ & 23 & 0,98 & $(0,6-1,5)$ & \\
$\quad$ Ikke inkludert i kohorten $(\mathrm{n}=389)$ & 25 & 0,79 & $(0,5-1,2)$ & \\
All død & & & & \\
$\quad$ Inkludert i kohorten $(\mathrm{n}=390)$ & 60 & 0,65 & $(0,5-0,8)$ & \\
$\quad$ Ikke inkludert i kohorten $(\mathrm{n}=389)$ & 179 & 1,22 & $(1,1-1,4)$ & \\
\hline
\end{tabular}

$£$ : SIR for kreftforekomst, SMR for dødelighet.

$€$ : P-verdi for forskjell i SIR/SMR mellom de som er inkludert i kohorten og de som ikke er inkludert.

$\S$ : Kreftformer med lav overlevelse er definert ved at de har mindre enn $50 \%$ fem års relativ overlevelse. Dette gjelder kreft i tunge, munnhule, svelg, spiserør, magesekk, bukspyttkjertel, lunge, nyre, hjerne og blod.

De 287 storby-feierne har i gjennomsnitt blitt fulgt opp, med hensyn på kreft, i 25,8 år. Personårene fordeler seg jevnt over perioden 1953-1998, med 3735 $(50,4 \%)$ av totalt 7407 personår før 1977. Tabell 2 viser at feiere i storbyene har en SIR på 1,33 for total kreft. Hvis storbyer brukes som referansepopulasjon isteden for hele landet, blir SIR redusert til 1,11. For de ulike kreftformene separat, blir de relative risikoene basert på kun få tilfeller. Gruppen av kreft i tunge, munnhule, svelg, spiserør, lever og strupehode har en signifikant høyere hyppighet blant storby-feierene, sammenliknet med hele populasjonen.

Dødeligheten i kohorten av storby-feiere er $20 \%$ høyere enn i hele landet, se Tabell 3. De har en overdødelighet av kreft, hjerteinfarkt og voldsomme dødsfall.

De 1292 personene som var feier i 1960, 1970 eller 1980 danner en egen kohort, og vi kan følge personene fra første gang de var med i Folke og Boligtellingen. Tabell 4 og 5 viser at disse ikke har noen signifikant overhyppighet av kreftforekomst eller dødelighet.

Tabell 2. SIR for subkohorten av storby-feiere ${ }^{\epsilon}$. Oppfølging fra 1953-1998.

\begin{tabular}{lcccc}
\hline Kreftform & $\begin{array}{c}\text { Obser- } \\
\text { vert } \\
\text { antall }\end{array}$ & $\begin{array}{c}\text { SIR } \\
\text { Nasjonale } \\
\text { rater }\end{array}$ & $\begin{array}{c}95 \% \\
\text { konfidens- } \\
\text { intervall }^{\S}\end{array}$ & $\begin{array}{c}\text { SIR } \\
\text { Lokale } \\
\text { rater }\end{array}$ \\
\hline $\begin{array}{l}\text { All kreft } \\
\text { Lunge }\end{array}$ & 46 & 1,33 & $(1,0-1,8)$ & 1,13 \\
Brysthinne & 7 & 1,72 & $(0,7-3,6)$ & 1,19 \\
Nyre & 0 & - & $(0,0-32)$ & - \\
Blære & 3 & 2,53 & $(0,5-7,4)$ & 1,96 \\
Hud & 1 & 0,44 & $(0,0-2,5)$ & 0,36 \\
Tunge, munnhule, & 1 & 0,85 & $(0,0-4,7)$ & 0,87 \\
svelg, spiserør, & & & & \\
lever og strupehode & 6 & 3,67 & $(1,4-8,0)$ & 2,16 \\
\hline
\end{tabular}

$€$ : Kohort på 287 feiere etablert ved å hente inn informasjon direkte fra kommunene.

$\S:$ Konfidensintervall for SIR med nasjonale rater.
Tabell 3. SMR for subkohorten av storby-feiere ${ }^{\epsilon}$. Oppfølging fra 1951-1996.

\begin{tabular}{lccc}
\hline & $\begin{array}{c}\text { Observert } \\
\text { antall }\end{array}$ & SMR & $\begin{array}{c}95 \% \\
\text { konfidens- } \\
\text { intervall }\end{array}$ \\
\hline Alle dødsårsaker & 113 & 1,20 & $(1,0-1,4)$ \\
Kreft & 31 & 1,51 & $(1,0-2,1)$ \\
Hjerteinfarkt & 38 & 1,39 & $(1,0-1,9)$ \\
Hjerteslag & 6 & 0,58 & $(0,2-1,3)$ \\
Andre sykdommer i & & & \\
sirkulasjonsorganene & 9 & 1,11 & $(0,5-2,1)$ \\
Bronkitt, emfysem og astma & 1 & 0,44 & $(0,0-2,4)$ \\
Andre sykdommer i & & & \\
åndedrettsorganene & 0 & - & $(0,0-0,8)$ \\
Andre sykdommer & 16 & 1,12 & $(0,6-1,8)$ \\
Voldsomme dødsfall & 12 & 1,86 & $(1,0-3,3)$ \\
\hline
\end{tabular}

$€$ : Kohort på 286 feiere etablert ved å hente inn informasjon direkte fra kommunene.

\section{DISKUSJON}

Kohorten av feiere ble etablert ved at hver enkelt kommune rapporterte inn sine nåværende og tidligere feiere. Et problem med denne metoden er at det er stor variasjon i rutiner for arkivering av informasjon om tidligere feiere i de enkelte kommuner. En kobling av kohorten mot infomasjon i Folke og Boligtellingen (FoB) viste at døde personer er underrapportert i kohorten og spesielt fra de mindre kommunene. Av den grunn kan ikke kohorten vurderes som pålitelig. Analysene er derfor begrenset til en subkohort bestående av feiere fra storbyer. SIR for total kreft i denne gruppen er 1,33 og SMR er 1,20. Usikkerheten rundt risikoene for de ulike kreftformene er stor, da beregningene baserer seg på svært få tilfeller. Blant alle feierne $\mathrm{i}$ FoB, er SIR for kreft samlet sett 1,02, mens SMR for dødelighet totalt er 1,03. Det er ikke signifikant økt risiko for noen kreftformer blant feierne i FoB. En stor nordisk studie (6) basert på folke og boligtellinger i 
1970, viser forhøyet risiko for kreft i magesekk (SIR = $1,5)$, lunge $(\mathrm{SIR}=1,3)$ og blære $(\mathrm{SIR}=1,5)$ for feiere $\mathrm{i}$ alle de nordiske landene samlet. I den svenske studien (2) har man observert økt risiko for kreft i spiserør $(\mathrm{SIR}=3,9)$, lunge $(\mathrm{SIR}=2,1)$ og blære $(\mathrm{SIR}=2,5)$. Disse forhøyede risikoene observeres også delvis blant våre storby-feiere, med SIR på 4,55 for kreft i spiserør (95\% KI 0,6-16) og SIR på 1,72 for lungekreft (95\% KI 0,7-3,6).

Kontroll av asbestfibrer i feiernes arbeidsmiljø (7), avdekker konsentrasjoner over Arbeidstilsynets administrative norm i 6 av 10 fyrrom. For kreft i brysthinne, kan ca $80 \%$ av tilfellene tilskrives asbest (8). I Sverige fant man 3 tilfeller av brysthinnekreft, mot forventet 0,6. I subkohorten av storby-feiere er det ikke observert noen tilfeller av brysthinnekreft, mot forventet antall 0,1.

Basert på det foreliggende, begrensede, norske materialet er det vanskelig å si noe sikkert om yrkesrelatert kreftrisiko og dødelighet blant norske feiere. Subkohorten av storby-feiere er for liten til å si noe om den historiske risikoen for kreft blant feiere, men analyser av kreft i munnhule og svelg viser en overrisiko i gruppen (6 observert mot 1,6 forventet). Tall fra Folke og Boligtellingene indikerer imidlertid at eventuelle overrisikoer for enkelte kreftformer ikke er betydelige. Det er heller ingen av dødsårsakene som skiller seg ut, med SMR rundt 1 for alle dødsårsakene for personer som er registrert som feier i FoB i 1960, 1970 eller 1980 .
Tabell 4. SIR for 1292 feiere i FoB 1960, 1970 eller 1980. Oppfølging fra 1960-1993.

\begin{tabular}{lrcc}
\hline Kreftform & $\begin{array}{c}\text { Observert } \\
\text { antall }\end{array}$ & SIR & $\begin{array}{c}95 \% \text { konfi- } \\
\text { densintervall }\end{array}$ \\
\hline All kreft & 151 & 1,02 & $(0,9-1,2)$ \\
Lunge & 26 & 1,28 & $(0,8-1,9)$ \\
Brysthinne & 0 & - & $(0,0-6,9)$ \\
Nyre & 4 & 0,72 & $(0,2-1,8)$ \\
Blære & 12 & 1,13 & $(0,6-2,0)$ \\
Hud & 3 & 0,71 & $(0,2-2,1)$ \\
Tunge, munnhule, svelg, & & & \\
spiserør, lever og strupehode & 11 & 1,47 & $(0,7-2,6)$ \\
\hline
\end{tabular}

Tabell 5. SMR for 1292 feiere i FoB 1960, 1970 eller 1980. Oppfølging fra 1966-1991.

\begin{tabular}{lccc}
\hline & $\begin{array}{c}\text { Observert } \\
\text { antall }\end{array}$ & SMR & $\begin{array}{c}95 \% \text { konfi- } \\
\text { densintervall }\end{array}$ \\
\hline Alle dødsårsaker & 374 & 1,03 & $(0,9-1,1)$ \\
Kreft & 96 & 1,11 & $(0,9-1,3)$ \\
Hjerteinfarkt & 126 & 1,05 & $(0,9-1,3)$ \\
Hjerteslag & 37 & 1,13 & $(0,8-1,6)$ \\
Andre sykdommer i & & & \\
sirkulasjonsorganene & 27 & 0,93 & $(0,6-1,4)$ \\
Bronkitt, emfysem og astma & 7 & 0,69 & $(0,3-1,4)$ \\
Andre sykdommer i & & & \\
åndedrettsorganene & 10 & 0,71 & $(0,3-1,3)$ \\
Andre sykdommer & 48 & 0,99 & $(0,7-1,3)$ \\
Voldsomme dødsfall & 23 & 1,06 & $(0,7-1,6)$ \\
\hline
\end{tabular}

\section{REFERANSER}

1. IARC. Soots. IARC Monogr Eval Carcinog Risk Chem Hum 1985; 35: 219-41.

2. Evanoff BA, Gustavsson P, Hogstedt C. Mortality and incidence of cancer in a cohort of Swedish chimney sweeps: an extended follow up study. Br J Ind Med 1993; 50: 450-9.

3. Eriksen I, Eriksen J V. Feiermesternes landsforening. Historisk beretning. 1995.

4. Breslow NE, Day NE. Statistical methods in cancer research. Volume II - The design and analysis of cohort studies. IARC Sci Publ 1987: 1-406.

5. Preston DL, Lubin J, Pierce DA, McConney ME. EPICURE. Seattle, WA: HiroSoft International Corporation, 1993.

6. Andersen A, Barlow L, Engeland A, Kjaerheim K, Lynge E, Pukkala E. Work-related cancer in the Nordic countries. Scand J Work Environ Health 1999; 25 Suppl 2: 1-116.

7. Johansen BV, Roos N. Feierundersøkelsen i Oslo. Kontroll av asbestfiber og svevestøv i feiernes arbeidsmiljø. 1991.

8. Dreyer L, Winther JF, Pukkala E, Andersen A. Avoidable cancers in the Nordic countries. Tobacco smoking. APMIS Suppl 1997; 76: 9-47. 